\title{
41. Data Feudalism: How Platforms Shape Cross-border Investigative Networks
}

\author{
Ştefan Cândea
}

\begin{abstract}
Data feudalism: How platforms shape cross-border investigative journalism and pave the way for its colonization.

Keywords: cross-border investigation, political economy of networking, sociotechnological access control, radical sharing, data feudalism, platforms
\end{abstract}

The platformization of cross-border investigative journalism is a growing phenomenon, endorsed by the same techno-positivism as the current trend of the platformization of society (Dijck et al., 2018). Platforms to host data for cross-border investigations began to gain prominence around 2010, in the context of doing investigations with leaked data. Perhaps the most notable example of a platform-based large-scale journalistic collaboration is the Pulitzer Prize-winning Panama Papers.

In order to organize data querying and reporting for the 500 journalists involved in the Panama Papers investigation, the International Consortium of Investigative Journalists (ICIJ) developed a platform called Global I-Hub (Wilson-Chapman, 2017). ${ }^{1}$ Ryle (2017) describes the platform as "specially developed technology.... used to interrogate and distribute information, connect journalists together in an online newsroom and ensure that the journalists work as one global team." It is called "the ICIJ virtual office... a Facebook for journalists" by both editorial and research staff of the ICIJ (Hare, 2016; Raab, 2016).

1 For a different perspective on the I-Hub platform, see Díaz-Struck, Gallego and Romera's chapter in this book.

Bounegru, L. and J. Gray (eds.), The Data Journalism Handbook: Towards a Critical Data Practice. Amsterdam: Amsterdam University Press, 2021 DOI 10.5117/9789462989511_CH41 
Data and cross-border investigations are supposed to be a perfect match and to empower independent journalistic collaborations (Coronel, 2016; Houston, 2016). Organizations such as the ICIJ, the Organised Crime and Corruption Reporting Project (OCCRP), and others, offer a hand-picked group of hundreds of journalists around the world, free (or, better said, subsidized) access to exclusive data sets available for querying on a private electronic platform, inaccessible to the outside world. They also offer a platform to publish and advertise the stories produced by these journalists.

For these organizations, using such platforms enables achieving scale and efficiency. For individual journalists, having exclusive and secure access in a single place to data troves of leaks, scraped company records, results of FOIA requests, archives, reporter notes, past stories, digitized prosecution files and court records - to name just a few-is a nirvana. This is especially true for those working in isolation and lacking the resources to travel and to store and process data.

While acknowledging these short-term benefits, critical research into how such investigative platforms are shaping the position and work of individual journalists who are using them and the networks they are part of, is yet to be developed.

There are consequences to having very few actors running such platforms and large numbers of journalists depending on them in the cross-border journalism realm. One of these could be understood as what in the landscape of "big tech" has been called a "hyper-modern form of feudalism" based on data ownership (Morozov, 2016). This concept draws attention to how total control of users' data and interactions is placed in the hands of a few companies who face no competition.

This model raises a number of concerns. An important one is access control. Access to such platforms is for many good reasons behind many layers of security and not every journalist can gain access. The essential question is who decides about who is included and excluded, and what the rules governing these decisions, and any tensions and conflicts that might emerge from them, are. Participation in such platforms is typically governed by a basic non-disclosure agreement or a partnership agreement, where the duties of the journalist or the media outlet receiving access are listed in detail, usually with scarce reference to their rights. Such systems and their governing schemes are not designed with co-ownership principles in mind, but rather as centrally owned structures, with surveillance of user activities and policing of agreement breaches as built-in features.

Moreover, adopting this model in investigative journalism, just as in the rest of the "sharing economy," runs the risk of generating a precariat 
within the realm of investigative journalism. Suggestive of this risk are the self-descriptions of some of the organizations running these platforms. For example, the OCCRP is describing itself as the "AirBnb or Uber of journalists" who want to do "great cross-border investigations" (OCCRP, 2017).

Indeed, often journalists are working without pay on data leaks owned by these organizations, having to pay for access to this data with their stories, and at any time running the risk of being removed from the platform. In spite of these unfavourable conditions, journalists increasingly have to be active on such platforms to stay in the game.

For these reasons, the business model for a major investigative network intermediary today may be seen as resembling that of a gig economy digital platform. Access to the platform can be revoked at any time, governance is not open for discussion, surveillance of user activity is built-in and "money is best kept out of the equation" (Buzenberg, 2015). The unpaid work and "radical sharing" interactions of hundreds of journalists are "sold" to donors, without profits being shared back. The ownership of the data leaks and the information exchange enriching such leaks is also not shared with users. Data produced by the information exchanged among users is only shared back under the form of features that would make the platform more efficient and thus would bring more interactions, more users and by extension more donors. The real cost of services is unknown to users.

What can be done to remedy this current trend in the investigative journalism world? A key first step is to acknowledge that platform-based data sharing in investigative journalism networks needs to be accompanied by discussions of governance rules and technology design, as well as co-ownership of data and digital tools. These networks need to develop and adopt public codes of conduct and to have accountability mechanisms in place to deal with abuses of any kind. The absence of these may amplify the precarious work conditions of individual journalists, instead of disrupting legacy media actors.

Secondly, the goal should not be to scale up a small number of cross-border investigative networks to thousands of people each. Rather, the goal should be to find a good model that can be applied to a multitude of independent networks that may collaborate with each other. So instead of a single network of 150 media partners, a more desirable approach would be to have ten networks of 15 partners each. The latter would be commensurate with the principles of a healthy media system, including fair competition and media pluralism. Without such approaches, the participatory potential of cross-border investigative networks will fail to materialize and, fuelled by a network effect, a few platforms will consolidate into a global investigative data-feudalism system. 


\section{Works Cited}

Buzenberg, W. E. (2015, July 6). Anatomy of a global investigation: Collaborative, data-driven, without borders. Shorenstein Center. https://shorensteincenter. org/anatomy-of-a-global-investigation-william-buzenberg/

Coronel, S. (2016, June 20). Coronel: A golden age of global muckraking at hand. Global Investigative Journalism Network. https://gijn. org/2016/o6/20/a-golden-age-of-global-muckraking/

Dijck, J. van, Poell, T., \& Waal, M. de. (2018). The platform society: Public values in a connective world. Oxford University Press.

Hare, K. (2016, April 4). How ICIJ got hundreds of journalists to collaborate on the Panama Papers. Poynter. https://www.poynter.org/reporting-editing/2016/ how-icij-got-hundreds-of-journalists-to-collaborate-on-the-panama-papers/

Houston, B. (2016, April 14). Panama papers showcase power of a global movement. Global Investigative Journalism Network. https://gijn.org/2016/04/13/ panama-papers-showcase-power-of-a-global-movement/

Morozov, E. (2016, April 24). Tech titans are busy privatising our data. The Guardian. https:/www.theguardian.com/commentisfree/2016/apr/24/ the-new-feudalism-silicon-valley-overlords-advertising-necessary-evil

OCCRP. (2017). 2016 Annual Report. OCCRP. https://ww w.occrp.org/documents/ AnnualReport2017.pdf

Raab, B. (2016, April 8). Behind the Panama Papers: A Q\&A with International Consortium of Investigative Journalists director Gerard Ryle. Ford Foundation. https://www.fordfoundation.org/ideas/equals-change-blog/posts/behindthe-panama-papers-a-qa-with-international-consortium-of-investigativejournalists-director-gerard-ryle/

Ryle, G. (2017, November 5). Paradise Papers: More documents, more reporters, more revelations. ICIJ. https://www.icij.org/blog/2017/11/ more-documents-more-journalists-and-bigger-revelations/

Wilson-Chapman, A. (2017, August 29). Panama Papers a "notable security success." ICIJ. https://www.icij.org/blog/2017/o8/panama-papers-notable-security-success/

\section{About the Author}

Ștefan Cândea is a doctoral researcher at CAMRI, University of Westminster, a member of the International Consortium of Investigative Journalists (ICIJ) and the coordinator of European Investigative Collaborations (EIC). 